\title{
The role of the neurohormonal system in heart failure
}

\author{
M Komajda, F Pousset, R Isnard, P Lechat
}

Congestive heart failure is a major health problem associated with high morbidity and mortality. Insights into the pathophysiology of this syndrome have changed considerably during the past decade. Heart failure is no longer considered to be a purely haemodynamic disorder but is regarded as a complex condition, characterised by a shift in the balance between opposite forces: the vasodilator-natriuretic mechanisms (natriuretic peptides, prostaglandins, vagal tone, nitric oxide pathway, and possibly adrenomedullin) and the vasoconstrictor-antinatriuretic mechanisms (catecholamines, angiotensin II, aldosterone, arginine-vasopressin, and endothelin) (fig 1). Moreover, activation of the neurohormonal systems in response to cardiac injury has a deleterious effect on the heart mediated via complex systemic and local mechanisms. These events precipitate functional and structural changes in the heart and peripheral vasculature, which ultimately cause the disease to progress.

\section{Activation of the neurohormonal systems} EXPERIMENTAL STUDIES

The time course of neurohormonal activation has been studied in a dog model of heart failure induced by rapid ventricular pacing. The model can be used to examine the effect of haemodynamic changes on the severity of heart failure by varying the rate of pacing. ${ }^{1}$

Plasma concentrations of atrial natriuretic peptide (ANP) and noradrenaline rise early after the onset of pacing and increase further as haemodynamic conditions deteriorate. ${ }^{1}$ Noradrenaline concentrations continue to rise throughout the pacing period but plasma ANP concentrations plateau. Plasma renin activity and aldosterone concentrations remain within the normal range in the early phase of heart failure and sodium excretion and renal function are maintained at pre-pacing concentrations.

It has been suggested that the dissociation in the time course of various neurohormonal

\footnotetext{
Department of Cardiology, La PitieSalpetriere Hospital and Association Claude Bernard, 47/83 Boulevard de 1'Hôpital, 75013 Paris, France

M Komajda

F Pousset

$\mathrm{R}$ Isnard

P Lechat

Correspondence to:

Dr Komajda.
}

$$
\begin{aligned}
& \text { Glossary } \\
& \text { CONSENSUS: Cooperative north } \\
& \text { Scandinavian enalapril survival study } \\
& \text { SAVE: Survival and ventricular enlarge- } \\
& \text { ment } \\
& \text { SOLVD: Studies of left ventricular dys- } \\
& \text { function } \\
& \text { V-HeFT II: Vasodilator heart failure trial II }
\end{aligned}
$$

systems is the result of an inhibitory effect of ANP on the renin-angiotensin system. ${ }^{1}$ In support of this hypothesis, a vena cava constriction model of heart failure in dogs, in which ANP is not activated, has shown that sodium excretion and renal blood flow are reduced, and that the renin-angiotensin system is activated. $^{2}$ Infusion of ANP restores renal function and prevents renin and aldosterone activation in these animals. These findings suggest that ANP plays an important role in the maintenance of sodium and water excretion, and in terms of suppressing the reninangiotensin system in the early phase of experimental heart failure.

Similar results have been reported in a canine model of asymptomatic left ventricular dysfunction in which raised plasma ANP and catecholamines are observed in the presence of normal plasma renin activity and aldosterone concentrations. ${ }^{3}$ Renal function remains normal in this model despite peripheral vasoconstriction. In another study using mild pacing to induce heart failure, the administration of a prostaglandin synthesis inhibitor, indomethacin, resulted in a significant decrease in renal blood flow and an increase in renal vascular resistance, indicating that prostaglandins may also be involved in the preservation of renal function by exerting a vasodilator effect on the renal vasculature. ${ }^{4}$

Activation of neurohormonal systems appears early after the onset of pacing induced heart failure: plasma concentrations of noradrenaline rise within hours or days and continue to rise throughout pacing. ${ }^{5}$ This response is associated with a decrease in myocardial noradrenaline content. ${ }^{6}$

In contrast, plasma ANP initially increases in response to raised filling pressures, but thereafter a plateau is reached. Further increases in ANP in response to volume expansion are abolished in established heart



Figure 1 Imbalance between vasoconstrictivel antinatriuretic and vasodilating/natriuretic forces in heart failure. 
failure, suggesting that ANP release has become maximal. ${ }^{78}$

Several sources of evidence suggest that blunting the renal and possibly the vascular effects of ANP are responsible for the deteriorating renal function that accompanies severe experimental heart failure..$^{9-11}$ For instance, the loss of natriuretic effect is accompanied by a normal plasma cGMP response to exogenous ANP infusion but there is no change in urinary cGMP excretion. ${ }^{11}$ Various mechanisms have been suggested to explain the blunted effect of ANP in severe heart failure, including downregulation of biological receptors, altered postreceptor signal transduction, decreased renal pressure, and activation of vasoconstrictive, fluid retaining neurohormonal mechanisms.

Findings from a rabbit model of heart failure show that renal hyporesponsiveness following ANP infusion is not associated with a decrease in renal receptor affinity or density (however, only global density was assessed including both clearance and biological receptors). The in vitro finding that the ability of glomeruli to produce cGMP was preserved after ANP incubation suggests that, at least in this model, the defect lies beyond the production of the second messenger cGMP. ${ }^{12}$

In severe stages of pacing induced heart failure, pronounced increases in plasma concentrations of renin and aldosterone accompany vasoconstriction, alteration in renal blood flow, sodium and fluid retention. Alterations in the renin-angiotensin-aldosterone system explain these modifications, as it has been shown that the increase in vascular resistance is blocked by angiotensin converting enzyme (ACE) inhibition, ${ }^{5}$ and that denervation of the kidneys does not prevent the development of sodium retention. ${ }^{13}$ Endothelial dysfunction and changes in endothelium dependent vasorelaxation are also observed and may participate in the progression of the disease ${ }^{14}{ }^{15}$ Moreover, the accompanying raised plasma concentrations of vasopressin that occur in end stage pacing induced heart failure exacerbate hyponatraemia. ${ }^{16} 17$

The endothelin system has been studied in a modified pacing model. ${ }^{18}$ Plasma concentrations of this peptide are slightly raised in moderate heart failure and increase more dramatically in severe heart failure. Endothelin-1 concentrations rose from $6.7 \mathrm{pg} / \mathrm{ml}$ in early left ventricular dysfunction, to $26.3 \mathrm{pg} / \mathrm{ml}$ in moderate left ventricular dysfunction, and to $33.4 \mathrm{pg} / \mathrm{ml}$ in severe left ventricular dysfunction.

\section{Clinical studies}

Neurohormonal data from the SOLVD study show that there is a progressive increase in plasma concentrations of renin, noradrenaline, aldosterone, and ANP from normal to asymptomatic left ventricular dysfunction, and from asymptomatic left ventricular dysfunction to overt heart failure. ${ }^{19}$ Interestingly, moderate increase of plasma renin activity in asymptomatic left ventricular dysfunction occurs only in patients receiving diuretics.

Neurohormonal activation has been reported in left ventricular dysfunction following acute myocardial infarction. ${ }^{20}$ Patients have significantly higher plasma concentrations of noradrenaline, vasopressin, and ANP and a higher renin activity than controls, although wide variations are observed in the degree of activation from one patient to the other. Interestingly, activation of one system does not correlate with activation of another.

\section{NEUROHORMONAL ACTIVATION AS A MARKER} OF SEVERITY

Several studies have shown that neurohormonal activation is related to the severity of left ventricular dysfunction. A substudy from the SOLVD registry found a weak, but significant, negative correlation between ejection fraction and increase in plasma noradrenaline, vasopressin, renin activity, and ANP in patients with asymptomatic left ventricular dysfunction or mild to moderate heart failure. When this relation was adjusted for New York Heart Association (NYHA) functional class and the use of diuretics or ACE inhibitors, the plasma vasopressin concentrations were no longer correlated to ejection fraction. The study also showed that neurohormonal activation was more closely related to left ventricular dysfunction than to functional class or concomitant drug treatment. ${ }^{21}$

Plasma noradrenaline, plasma renin activity, vasopressin, and ANP were also significantly increased in a subgroup of patients from the SAVE study who had asymptomatic left ventricular dysfunction after myocardial infarction. ${ }^{20}$ The clinical variables most closely associated with neurohormonal activation were Killip class, ejection fraction, and use of diuretics. In another postmyocardial infarction study, plasma ANP and N-ANP (but not brain natriuretic peptide (BNP)) were significantly associated with a left ventricular ejection fraction $\leqslant 45 \% .{ }^{22}$ The study concluded that plasma ANP determined three days after an acute myocardial infarction was an excellent predictor of left ventricular dysfunction.

The N-terminal fragment (1-98) pro-ANP is released on an equimolar basis with the Cterminal (99-126) active hormone and can be assayed more simply owing to its superior in vitro stability. A study of 202 heart failure patients showed that pro-ANP was more closely correlated with NYHA class than other haemodynamic variables. ${ }^{23}$ In the same study there was a significant inverse correlation between pro-ANP and ejection fraction. A second study has reported a progressive increase in plasma pro-ANP as disease progresses from asymptomatic to severe left ventricular dysfunction. ${ }^{24}$

An increase of plasma endothelin has been reported in one study of severe heart failure patients (NYHA class III-IV). The increase in this marker was related principally to an increase of the precursor big endothelin. ${ }^{25}$ In this study there was an inverse correlation between plasma endothelin and left ventricular ejection fraction. In another study, raised immunoreactive endothelin-1 was specifically correlated with the extent of pulmonary hyper- 
tension in a group of patients with mild to severe heart failure. ${ }^{26}$

Furthermore, neurohormonal activation in patients with isolated right ventricular failure and primary pulmonary hypertension who had raised concentrations of plasma noradrenaline or endothelin was found to be correlated to the severity of the haemodynamic disorder. ${ }^{27}$

Thus there is a wide body of evidence to suggest that neurohormonal activation occurs in the early stages of clinical heart failure and that it is a good predictor of both functional and haemodynamic severity.

\section{NEUROHORMONAL ACTIVATION AS A MARKER} OF PROGNOSIS

The activation of various neurohormonal systems has been recognised as a valuable index for the prediction of cardiovascular mortality associated with congestive heart failure. Sympathetic activation assessed by the determination of plasma noradrenaline is thought to be predictive of a poor prognosis. ${ }^{28}$ In VHeFT II plasma noradrenaline was an independent risk factor in a cohort of male patients with mild to moderate heart failure; a plasma noradrenaline concentration $>900 \mathrm{pg} / \mathrm{ml}$ was associated with poor prognosis. ${ }^{29}$

Increased plasma ANP (>125 pg/ml) has been linked with high mortality in moderate heart failure. ${ }^{30}$ The CONSENSUS study in severe heart failure showed that the highest mortality rate occurred in patients with the highest increases in plasma noradrenaline, ANP, and renin activity. ${ }^{31}$

Increased concentrations of endothelin-1 or big endothelin have also been associated with poor prognosis in moderate or severe heart failure, and are among the most powerful predictors of mortality among all the clinical haemodynamic or hormonal variables studied. ${ }^{32-34}$

The predictive value of neurohormonal stimulation has been established consistently among postmyocardial infarction patients with left ventricular dysfunction. In the SAVE trial, plasma renin activity and ANP at the time of hospital discharge were the only independent predictors of cardiovascular mortality. ${ }^{35}$ Plasma renin activity, ANP, aldosterone, and arginine vasopressin were all independent predictors of the combined end points of cardiovascular mortality, occurrence of severe heart failure, or recurrence of myocardial infarction. Supportive data have been obtained from a second study conducted in 145 patients with documented acute myocardial infarction. In this trial plasma ANP and endothelin concentrations added prognostic information to that obtained from clinical evaluation but not to that obtained from left ventricular ejection fraction. ${ }^{36}$

In the SAVE trial, N-terminal pro-ANP, unlike ANP and other neurohormones, was a powerful independent predictor of cardiovascular mortality and the development of heart failure, when other clinical variables or ejection fraction were included as covariates in the statistical model..$^{37}$

Plasma BNP has recently been shown to provide important independent prognostic information. ANP is a better predictor of left ventricular dysfunction; however, in postmyocardial infarction patients plasma BNP is a better marker of mortality than either ANP or pro-ANP. ${ }^{22}$ Various hypotheses have been formulated to explain this finding.

One possibility is that because the secretion of BNP, but not of ANP, is significantly greater in the infarcted region than in the noninfarcted region of the left ventricle this marker may more accurately reflect regional wall stress in the left ventricle than ANP. ${ }^{38}$

\section{OTHER POTENTIAL NEUROHORMONAL} RELATIONS

It has been proposed that other factors may play a role in the setting of clinical heart failure as the autonomic imbalance observed in this disease is not only characterised by enhanced sympathetic tone but also by parasympathetic withdrawal..$^{39}$ A significant reduction in the parasympathetic mediated high frequency area, and in the ratio of high:low frequency area, was demonstrated in a group of patients with idiopathic dilated cardiomyopathy, using a technique of spectral analysis to study heart rate variability. ${ }^{41}$

There is reduced vasodilatory responses to intra-arterial administration of acetylcholine in patients with congestive heart failure, suggesting that endothelium dependent vasodilation in the peripheral circulation is impaired. ${ }^{42}$ The authors suggested that this is the result of several coexistent abnormalities, including abnormal production of cyclo-oxygenase dependent vasoconstricting factor, impaired endothelial release of nitric oxide, and decreased vascular smooth muscle responsiveness to cGMP mediated vasodilatation.

Following observations that plasma concentration of various cytokines are increased in patients with myocarditis or idiopathic cardiomyopathy, it was recently demonstrated that patients with heart failure have raised concentrations of antigenic tumour necrosis factor $\alpha(\mathrm{TNF} \alpha)$ and of other cytokines. The magnitude of these increases was related to the clinical, haemodynamic, and neurohormonal severity of the disease. ${ }^{43}{ }^{44}$ Disease severity was also associated with high concentrations of a soluble form of the TNF receptor, expected to act as a TNF antagonist.

TNF has many potential effects including induction of endothelial dysfunction, production of free oxygen radicals, and acceleration of the catabolism of skeletal muscle. TNF also enhances the expression of the inducible nitric oxide synthase. ${ }^{45}$ This is turn has the potential to inhibit the contractility of myocardial cells or trigger apoptosis, a phenomenon recently demonstrated in failing heart muscle. ${ }^{46}$ Although preliminary, these findings suggest that in addition to classic neurohormonal factors, other mediators such as cytokines may play a role in the development and the progression of the disease.

Adrenomedullin is a potent endogenous natriuretic and vasodilating peptide originally isolated from extracts of human pheochromo- 
Table 1 Summary of the physiological and pathophysiological effects of the sympathetic nervous system, angiotensin II, and endothelin

\begin{tabular}{|c|c|c|}
\hline Sympathetic nervous system & Angiotensin II & Endothelin \\
\hline Direct toxic effect on the myocardium & Vasoconstriction & Vasoconstriction \\
\hline $\begin{array}{l}\text { Increased cAMP results in intracellular } \\
\text { calcium release with an increased risk } \\
\text { of arrhythmia }\end{array}$ & $\begin{array}{l}\text { Increased aldosterone secretion, } \\
\text { increased inotropy }\end{array}$ & $\begin{array}{l}\text { Increased angiotensin II } \\
\text { release, initiation of growth } \\
\text { programme }\end{array}$ \\
\hline Peripheral vasoconstriction & Sympathetic activation & $\begin{array}{l}\text { Increased hypertrophy of cardiac } \\
\text { and vascular muscle }\end{array}$ \\
\hline Increased renin activity & Myocyte hypertrophy & Increased aldosterone release \\
\hline \multirow[t]{2}{*}{$\begin{array}{l}\text { Increased myocardial oxygen demand } \\
\text { (increased heart rate and inotropy) }\end{array}$} & $\begin{array}{l}\text { Smooth muscle cell hypertrophy } \\
\text { and proliferation }\end{array}$ & $\begin{array}{l}\text { Increased heart rate, increased } \\
\text { inotropy, reduced renal flow, } \\
\text { reduced glomerular filtration } \\
\text { rate, reduced sodium excretion }\end{array}$ \\
\hline & Increased collagen content & \\
\hline
\end{tabular}

cytoma. The peptide has been localised in endothelial cells, in the kidney, and in the heart. The effects of adrenomedullin are mediated by the generation of cAMP.

Plasma adrenomedullin concentrations have been shown to be increased in patients with congestive heart failure, ${ }^{47}$ and the immunoreactivity of adrenomedullin is significantly more intense in the ventricular myocytes from failing hearts than in those from normal hearts. These findings support a potential role for this natriuretic and vasodilating agent in the neuroactivation of congestive heart failure. Its exact pathophysiological role has yet to be established.

A recent study showed that plasma concentrations of adrenomedullin increased progressively in patients with class II to class IV heart failure, and were correlated with plasma noradrenaline, ANP, and BNP concentrations, suggesting that activation of the sympathetic system and increased plasma volume are involved in its secretion. ${ }^{48}$

Exogenous adrenomedullin has been shown to exert a potent and long lasting vasodilatory effect on skeletal muscle arteries in normal subjects. This response is mediated via the nitric oxide pathway, as administration of the antagonist L-nitromonomethyl-L-arginine (LNMMA) significantly attenuates the observed effect. This is consistent with the finding that the vascular effects of adrenomedullin were significantly blunted in heart failure patients, partly because of the impaired production of nitric oxide in the forearm resistance vessels of these patients. ${ }^{49}$

PATHOPHYSIOLOGICAL IMPLICATIONS

As shown in table 1, the potential deleterious (or beneficial) effect of neurohormonal activation is not limited to a simple imbalance between vasodilating/natriuretic (that is, natri-

Figure 2 Functional and structural modifications following neurohormonal stimulation in heart failure.
Functional modifications Structural modifications

$$
\begin{aligned}
& \text {-Inotropy } \uparrow \quad-H y p e r t r o p h y \\
& \text {-Heart rate } \uparrow \\
& \text {-Vasoconstriction } \\
& \text {-Water/salt retention } \\
& \uparrow \text { Non-muscular tissue } \\
& \checkmark \text { Adult cardiac } \\
& \text { genes expression } \\
& \text {-Energy demand } 4 \\
& \text {-Altered loading conditions } \\
& \text {-Altered vascular/diastolic properties } \\
& \text {-Proarrhythmogenic effect }
\end{aligned}
$$

uretic peptides, adrenomedullin, nitric oxide) and vasoconstrictive/antinatriuretic forces (that is, sympathetic nervous system, reninangiotensin-aldosterone system, endothelin, arginine vasopressin). For example, angiotensin II is not only a potent inotropic and vasoconstricting agent, it also promotes smooth muscle cell hypertrophy, ${ }^{50}$ cardiac myocyte hypertrophy, and proliferation, ${ }^{5152}$ and increases intramyocardial collagen content either directly or through an aldosterone mediated effect. ${ }^{3354}$

Endothelin promotes myocyte growth resulting in cardiac hypertrophy and affects collagen synthesis and degradation. ${ }^{55} 56$ Through mechanisms such as these, neurohormonal activation induces functional and structural modifications of the heart and peripheral vasculature, ultimately resulting in hypertrophy and fibrosis (figs 2 and 3 ).

Local activation of neurohormonal systems within cardiac and vascular tissue is at least as important as systemic activation. In the rat myocardial infarction model of heart failure there is early activation of the genes that code for the major proteins of the renin-angiotensin system or that promote their expression. This results in an increased production of

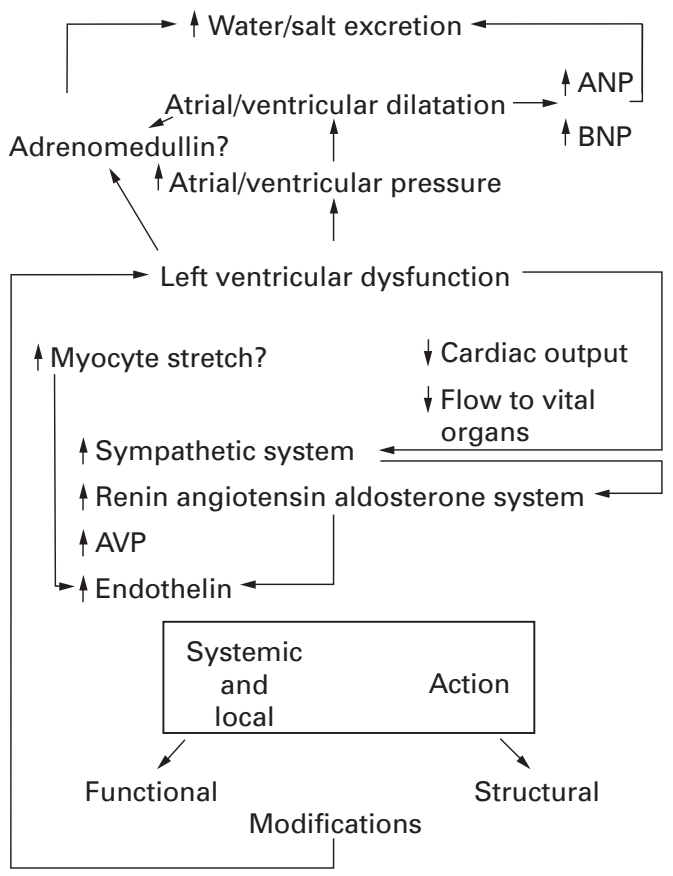

Figure 3 Schematic representation of the activation of neurohormonal systems in heart failure. 
angiotensinogen (AT) and an increased density of $\mathrm{AT}_{1}$ receptors. ${ }^{57-59}$

Activation of the cardiac renin-angiotensin system also occurs in the early stage of experimental heart failure as shown by the increase in ACE activity in the left ventricle three days after induction, whereas plasma ACE activity remains normal. ${ }^{60}$

Infusion of noradrenaline induces a rapid ventricular expression of endothelin-1 mRNA, which in the rat model is increased on day $1 .{ }^{61}$ These findings suggest that endogenous endothelin-1 plays a role in mediating noradrenaline induced ventricular hypertrophy.

In the rat model of congestive heart failure induced by ligation of the left coronary artery, not only are plasma endothelin-1 concentrations significantly higher than in control animals, but so is the expression of the mRNA for pre-proendothelin-1, the peptide itself, and the density of endothelin receptors in the left ventricle. ${ }^{62}$ This study suggests that myocardial production of endothelin-1 is significantly increased in cardiac failure, suggesting that the endothelin transduction system is activated in a manner that enables endogenous endothelin-1 to participate in the maintenance of cardiac function following myocardial injury.

A rapid increase of ventricular BNP expression is observed as early as 12 hours after coronary ligation in the rat model, whereas left ventricular ANP concentrations remain unchanged during the first day. ${ }^{63}$ In patients with dilated cardiomyopathy, ANP, which under normal conditions is secreted mainly by the atria, is also secreted by the left ventricle. Local concentrations of ANP and BNP increase in proportion to the severity of disease. ${ }^{64}$

These findings show that local as well as systemic systems play an important role in the modulation of cardiac and vascular function. The local neurohormones are generated either by cardiac myocytes, mesenchymal or endothelial cells. The tissue autocrine and paracrine mechanisms that are activated following injury have the potential to induce local responses that are involved in the initiation of hypertrophy and fibrosis, and in the remodelling process. In this way they facilitate the progression of heart failure.

\section{Unresolved issues}

Many issues remain unsolved regarding the role of neurohormonal activation in patients with diastolic heart failure, which is an increasing health problem. It has been suggested that plasma renin activity, aldosterone, and angiotensin II remain within the normal range in patients with diastolic heart failure, whereas they increase in patients with systolic heart failure. ${ }^{65}$ The effect of aging is also poorly understood. In a group of 40 patients over 75 years old with impaired systolic function, plasma noradrenaline was higher than in younger patients, and plasma active renin, angiotensin II, and ANP were lower than in younger patients. In the same study, healthy elderly patients had raised plasma noradrenaline con-
Table 2 Influence of heart failure drugs on neurohormonal status

\begin{tabular}{ll}
\hline Inhibition & Stimulation \\
\hline ACE inhibitors & Diuretics \\
Renin inhibitors & $\beta$ Agonists \\
AT $_{\text {receptor antagonists }}$ & Direct vasodilators \\
Neutral endopeptidase inhibitors & \\
Endothelin receptor antagonists & \\
AVP antagonists & \\
Digitalis? & \\
\hline
\end{tabular}

centrations. ${ }^{66}$ The prognostic implications of these observations is yet to be determined but the observed differences suggest that these indices may have different predictive values in younger and elderly patients.

The influence of treatment on neurohormonal activation in heart failure is also poorly understood. As neurohormonal activation is a major component of the prognosis and progression of the disease, it appears desirable to administer agents that modulate neuroendocrine activity and avoid those that result in neurohormonal stimulation (table 2). Raised plasma renin activity and aldosterone secretion has been reported in moderate heart failure following administration of frusemide. This suggests that the role of diuretics as first line treatment for congestive heart failure is questionable. The use of these agents should almost certainly be restricted to the management of discreet periods of overt fluid retention, and lowered to the minimal effective dose once the acute phase of fluid retention is controlled. ${ }^{67}$

Vasodilators are the second class of drugs likely to induce neurohormonal stimulation. Prazosin alters haemodynamic status by stimulating the renin-angiotensin-aldosterone system. However, the chronic effects of this drug remain the subject of debate. ${ }^{6869}$ Studies with the direct vasodilator flosequinan indicate that, despite it inducing a favourable haemodynamic effect, it results in significant stimulation of the sympathetic and the renin-angiotensin systems after 10 days of administration. ${ }^{70}$

Little is known about how neurohormonal stimulation progresses with advancing disease. Sequential determinations in patients participating in the V-HeFT II trial indicate an early and progressive rise in noradrenaline in patients receiving hydralazine and isosorbide dinitrate, whereas no changes occurred in those treated with enalapril during the first year. Subsequent determinations showed that noradrenaline increased progressively with both treatment regimens, suggesting that neuroendocrine activation progresses despite treatment. ${ }^{29}$

The increasing use of $\beta$ blockers, and the development of new drugs such as neutral endopeptidase antagonists and endothelin receptor inhibitors, highlight the need to determine the chronic effect of treatment in terms of preventing neurohormonal activation.

\section{Conclusions}

Neurohormonal activation occurs in a broad spectrum of experimental models as well as in patients with congestive heart failure. This early phenomenon is triggered by left ventricu- 
lar dysfunction. The complex synergistic and antagonist relation that exists between the various neurohormonal systems, coupled with a variety of local and systemic effects, results in functional and structural modifications, which ultimately accelerate disease progression.

Data from large clinical trials suggests that drugs that modulate neurohormonal stimulation have a long term beneficial effect in patients with congestive heart failure. However, additional information is needed for the evaluation of the newer classes of drugs.

1 Elsner D. Changes in neurohumoral systems during the development of congestive heart failure: impact on cardiovascular and renal function. Eur Heart f 1995;16 (suppl N):52-8

2 Lee ME, Miller WL, Edwards BS, et al. Role of endogenous atrial natriuretic factor in acute congestive heart failure. 7 Clin Invest 1989;84:1962-6.

3 Redfield MM, Aarhus LL, Wright RS, et al. Cardiorenal and neurohumoral function in a canine model of early left ventricular dysfunction. Circulation 1993;87: 2016-22.

4 Riegger GAJ, Elsner D, Kromer EP. Circulatory and rena control by prostaglandins and renin in low cardiac output in dogs. Am F Physiol 1989;256:H1079-86.

5 Riegger GAJ, Liebau G, Holzschuh M, et al. Role of the renin-angiotensin system in the development of congestive heart failure in the dog as assessed by chronic converting-enzyme blockade. Am f Cardiol 1984:53:614-18.

6 Armstrong PW, Stopps TP, Ford SE, et al. Rapid ventricular pacing in the dog: pathophysiologic studies of heart lar pacing in the dog: pathophysiologic

7 Redfield MM, Edwards BS, McGoon, et al. Failure of atrial natriuretic factor to increase with volume expansion in acute and chronic congestive heart failure in the dog. acute and chronic conges

8 Moe GW, Grima EA, Angus C, et al. Response of atria natriuretic factor to acute and chronic increases of atrial pressures in experimental heart failure in dogs. Circulation 1991;83:1780-7.

9 Riegger GAJ, Elsner D, Kromer EP, et al. Atrial natriuretic peptide in congestive heart failure in the dog: plasma levels, cyclic guanosine monophosphate, ultrastructure of atrial myoendocrine cells, and hemodynamic, hormonal, and renal effects. Circulation 1988;77:398-406.

10 Moe GW, Forster C, De Bold AJ, et al. Pharmacokinetics, hemodynamic, renal and neurohormonal effects of atria natriuretic factor in experimental heart failure. Clin Invest Med 1990;13:111-18.

11 Margulies KB, Heublein DM, Perrella MA, et al. ANFmediated renal cGMP generation in congestive heart failure. Am f Physiol 1991;260:F562-8.

12 Isnard R, Carayon A, Eurin J, et al. Glomerular atrial natriuretic factor receptors in experimental congestive heart failure. Am f Physiol 1993, H9233-8.

13 Mizelle HL, Hall JE, Montani JP. Role of renal nerves in control of sodium excretion in chronic congestive heart failure. Am f Physiol 1989;256:F1084-93.

14 Kiuchi K, Sato N, Shannon RP, et al. Depressed betaadrenergic receptor and endothelium-mediated vasodilation in conscious dogs with heart failure. Circ Res 1993; 73:1013-23.

15 Wang J, Seyedi N, Xu X, et al. Defective endotheliummediated control of coronary circulation in conscious mediated control of coronary circulation in conscious

16 Riegger GAJ, Liebau G. The renin-angiotensin-aldosterone system, antidiuretic hormone and sympathetic nerve activity in an experimental model of congestive heart failure in the dog. Clin Sci 1982:62:465-9.

17 Travill CM, Williams TDM, Pate P, et al. Haemodynamic and neurohumoral response in heart failure produced by rapid ventricular pacing. Cardiovasc Res 1992;26:783-90.

18 Stevens TL, Borgeson DD, Redfield MM, et al. Characterization of neurohumoral activation in a unique model of progressive left ventricular dysfunction [abstract]. First international meeting of the working group on heart failure of the European Society of Cardiology, Amsterdam, 1995:P351.

19 Francis GS, Benedict C, Phil D, et al, for the SOLVD Investigators. Comparison of neuroendocrine activation investigators. Comparison of neuroendocrine activation in patients with left ventricular dysfunction with and
without congestive heart failure. A substudy of the studies without congestive heart failure. A substudy of the studies of left ventricular

20 Rouleau JL, DeChamplain J, Klein M, et al. Activation of neurohumoral systems in postinfarction left ventricula dysfunction. F Am Coll Cardiol 1993;22:390-8.

21 Benedict CR, Phil D, Johnstone DE, et al, for the SOLVD investigators. Relation of neurohumoral activation to clinical variables and degree of ventricular dysfunction: a report from the registry of studies of left ventricular dysfunction. 7 Am Coll Cardiol 1994;23:1410-20.

22 Omland T, Aakvaag A, Bonarjee Vernon VS, et al. Plasma brain natriuretic peptide as an indicator of left ventricular systolic function and long-term survival after acute myocardial infarction. Circulation 1996;93:1963-9.

23 Dickstein K, Larsen AI, Bonarjee V, et al. Plasma proatria natriuretic factor is predictive of clinical status in patients with congestive heart failure. Am 7 Cardiol 1995;76: $679-83$

24 Azizi C, Maistre G, Kalotka H, et al. Plasma levels and molecular forms of proatrial natriuretic peptides in healthy subjects and in patients with congestive heart failure. F Endocrinol 1996;10:561-5.

25 Wei CM, Lerman A, Rodeheffer RJ, et al. Endothelin in human congestive heart failure. Circulation 1994;89: $1580-6$

26 Cody RJ, Haas GJ, Binkley PF, et al. Plasma endothelin correlates with the extent of pulmonary hypertension in patients with chronic congestive heart failure. Circulation 1992;85:504-9.

27 Nootens M, Kaufmann E, Rector TS, et al. Neurohormonal activation in patients with right ventricula failure from pulmonary hypertension: relation to hemodynamic variables and endothelin levels. $7 \mathrm{Am}$ Coll Cardiol 1995;26:1581-5.

28 Cohn JN, Levine TB, Olivari MT, et al. Plasma norepinephrine as a guide to prognosis in patients with chronic congestive heart failure. N Engl f Med 1984;311:819-23.

29 Francis GS, Cahn IN, Johnon G et al for the V-HeFT VA Cooperative Studies Group. Plasma norepinephrine, plasma renin activity, and congestive heart failure. Relations to survival and the effects of therapy in $\mathrm{V}$ HeFT II. Circulation 1993;87(suppl VI):VI-40-8.

30 Gottlieb S, Kukin ML, Ahern D, et al. Prognostic importance of atrial natriuretic peptide in patients with chronic heart failure. f Am Coll Cardiol 1989;13:1534-9.

31 Swedberg K, Eneroth P, Kjekshus J, et al, CONSENSUS Trial Study Group. Hormones regulating cardiovascular function in patients with severe congestive heart failure and their relation to mortality. Circulation 1990;82: 1730-6.

32 Tsutamoto T, Hisanaga T, Fukai D, et al. Prognostic value of plasma soluble intercellular adhesion molecule- 1 and endotelin- 1 concentration in patients with chronic conendotelin-1 concentration in patients with chron

33 Pacher R, Stanek B, Hülsmann $M$, et al. Prognostic impact of big endothelin-1 plasma concentrations compared with invasive hemodynamic evaluation in severe heart failure. 7 Am Coll Cardiol 1996;27:633-41.

34 Pousset $\mathrm{F}$, Isnard $\mathrm{R}$, Lechat $\mathrm{Ph}$, et al. Prognostic value of plasma endothelin-1 in patients with chronic heart failure. Eur Heart $\mathcal{F}$ 1997;18:254-8.

35 Rouleau JL, Packer M, Moyé L, et al. Prognostic value of neurohumoral activation in patients with an acute myocardial infarction: effect of captopril. $f \mathrm{Am} \mathrm{Coll}$ Cardiol 1994;24:583-91.

36 Omland T, Bonarjee Vernon VS, et al. Neurohumoral measurements as indicators of long-term prognosis after acute myocardial infarction. Am f Cardiol 1995;76: 230-5.

37 Hall C, Rouleau JL, Moyé L, et al. N-terminal proatrial natriuretic factor. An independent predictor of long-term prognosis after myocardial infarction. Circulation 1994, 89:1934-42.

38 Sumida H, Yasue H, Yoshimura M, et al. Comparison of secretion pattern between A-type and B-type natriuretic peptides in patients with old myocardial infarction. $\mathcal{F} A m$ Coll Cardiol 1995;25:1105-10.

39 Porter T. Eckberg D, Fritsch J, et al. Autonomic pathophysiology in heart failure patients. F Clin Invest 1990; 85:1362-71.

40 Eckberg DL, Drabinsky M, Braunwald E. Defective cardiac parasympathetic control in heart disease. $N$ Engl $f$ Med 1971;285:877-83.

41 Binkley PF, Nunziata E, Haas GJ, et al. Parasympathetic withdrawal is an integral component of autonomic imbalance in congestive heart failure: demonstration in human subjects and verification in a paced canine model of ventricular failure $7 \mathrm{Am}$ Coll Cardiol 1991;18:464-72.

42 Katz SD, Schwartz M, Yuen J, et al. Impaired acetylcholine-mediated vasodilation in patients with congestive heart failure. Role of endothelium-derived vasodilating and vasoconstricting factors. Circulation 1993;88:55-61.

43 Ferrari R, Bachetti T, Confortini R, et al. Tumor necrosis factor soluble receptors in patients with various degrees of congestive heart failure. Circulation 1995;92:1479-86.

44 Testa M, Yeh M, Lee P, et al. Circulating levels of cytokines and their endogenous modulators in patients with mild to severe congestive heart failure due to coronary artery disease of hypertension. F Am Coll Cardiol 1996; 28:964-71.

45 Packer $M$. Is tumor necrosis factor an important neurohormonal mechanism in chronic heart failure ? Circulation monal mechanism

46 Narula J, Haider N, Virmani R, et al. Apoptosis in myocytes in end-stage heart failure. $N$ Engl $\mathscr{f}$ Med 1996; 335:1182-9.

47 Jougasaki M, Wei CM, Mc Kinley L, et al. Elevation of circulating and ventricular adrenomedullin in human congestive heart failure. Circulation 1995;92:286-9.

48 Nishikimi T, Saito Y, Kitamura K, et al. Increased plasma levels of adrenomedullin in patients with heart failure. $f$ Am Coll Cardiol 1995;26:1424-31.

49 Nakamura M, Yoshida H, Makita S, et al. Potent and longlasting vasodilatory effects of adrenomedullin in humans. Comparisons between normal subjects and patients with Comparisons between normal subjects and patient
chronic heart failure. Circulation 1997;95:1214-21.

50 Geisterfer A, Peach MJ, Owens GK. Angiotensin II 
induces hypertrophy not hyperplasia of cultured rat aortic smooth muscle cells. Circ Res 1988;62:749-56.

51 Khairallah PA, Kanabus J. Angiotensin and myocardia protein synthesis. In: Tarazi RC, Dunbard JB, eds. Perspectives in cardiovascular research. New-York: Raven Press, 1983:337-47.

52 Baker KM, Aceto JF. Angiotensin II stimulation of protein synthesis and cell growth in chick heart cells. Am $\mathcal{F}$ Physiol 1990;259:H610-18.

53 Kato H, Suzuki H, Tajima S, et al. Angiotensin II stimulates collagen synthesis in the cultured vascular smooth muscle cells. F Hypertension 1991;9:17-22.

54 Brilla CG, Guarda E, Zhou G, et al. Angiotensin II-mediated aldosterone synthesis in aortic endothelial cells [abstract]. Circulation 1992;86:90.

55 Shubetai HE, Mc Donough PM, Harris AN. Endothelin induction of inositol phospholipid hydrolysis, sarcomere assembly and cardiac gene expression in ventricula myocytes: a paracrine mechanism for myocardial cell hypertrophy. F Biol Chem 1990;65:2130-203.

56 Guarda E, Katwa LC, Myers PR, et al. Effects of endothelin on collagen turnover in cardiac fibroblasts. Cardiovasc Res 1993;27:2130-4.

57 Hirsch AT, Talsness CE, Schunkert H, et al. Tissue-specific activation of cardiac angiotensin converting enzyme in cific activation of cardiac angiotensin converting enzym

58 Lindpainter K, Lu W, Niedermajer N, et al. Selective activation of cardiac angiotensinogen gene expression in post-infarction ventricular remodeling in the rat. $f \mathrm{Mo}$ Cell Cardiol 1993;25:133-43.

59 Reiss K, Capasso JM, Huang H, et al. Angiotensin II receptors, c-myc, and c-jun in myocytes after myocardial infarction and ventricular failure. Am $\mathcal{f}$ Physiol 1993; 264:H760-9.

60 Pinto YM, De Smett BGJL, Van Gilst WH, et al. Selective and time related activation of the cardiac renin angiotensin system after experimental heart failure: relation to ventricular function and morphology. Cardiovasc Res 1993;27:1933-8.

61 Kaddoura S, Firth JD, Boheler KR, et al. Endothelin-1 is involved in norepinephrine-induced ventricular hypertro- phy in vivo. Acute effects of bosentan, an orally active, mixed endothelin ETA and ETB receptor antagonist. Circulation 1996;93:2068-79.

62 Sakai S, Miyauchi T, Sakurai T, et al. Endogenous endothelin-1 participates in the maintenance of cardiac function in rats with congestive heart failure Marked increase in endothelin-1 production in the failing heart. Circulation 1996;93:1214-22.

63 Hama N, Itoh H, Shirakami G, et al. Rapid ventricular induction of brain natriuretic peptide gene expression in induction of brain natriuretic peptide gene expression in 1995;92:1558-64.

64 Yasue H, Yoshimura M, Sumida H, et al. Localization and mechanism of secretion of B-type natriuretic peptide in comparison with those of A-type natriuretic peptide in normal subjects and patients with heart failure. Circulation 1994;90:195-203.

65 Kitzman DW, Wesley D, Rayburn Barry K, et al. Nonadrenergic neurohormonal activity in elderly patients with heart failure due to primary systolic vs. Primary diastolic left ventricular dysfunction [abstract]. Circulation 1995;92 (suppl I):I-667.

66 Dutka DP, Olivotto I, Ward S, et al. Effects of aging on neuroendocrine activation in subjects and patients in the presense and absence of heart failure with left ventricular presense and absence of heart failure with left ventricular

67 Bayliss J, Norell M, Canepa-Anson R, et al. Untreated heart failure: clinical and neuroendocrine effects of introheart failure: clinical and neuroendocrine eff
ducing diuretics. Br Heart $\mathcal{F} 1987 ; 57: 17-22$

68 Packer M. Role of the renin-angiotensin system in the development of haemodynamic and clinical tolerance to long-term prazosin therapy in patients with severe chronic heart failure. $\mathcal{F}$ Am Coll Cardiol 1986;7:671-80.

69 Riegger GAJ, Haeske W, Kraus C, et al. Contribution of the renin-angiotensin-altosterone system to developmen of tolerance and fluid retention in chronic congestive heart failure during prazosin treatment. Am $\mathcal{f}$ Cardiol 1987;59:906-10.

70 Isnard $\mathrm{R}$, Lechat $\mathrm{Ph}$, Pousset $\mathrm{F}$, et al. Hemodynamic and neurohormonal effects of Flosequinan in patients with heart failure. Fundam Clin Pharmacol 1997;11:83-9. 